\title{
Distance Learning in Undergraduate Education: Methods, Opportunities, and Challenges for Institutions and Educators
}

\author{
J. Ross Maclean ${ }^{\mathrm{a}-\mathrm{c}}$ Pat McShane ${ }^{\mathrm{a}}$ Jeff Etchason ${ }^{\mathrm{a}-\mathrm{c}}$ \\ a School of Medicine, Medical College of Georgia, Augusta, Ga., ${ }^{b}$ Kerr L. White Institute for Health Services Research, \\ Decatur, Ga., 'Center for Healthcare Improvement, BlueCross and BlueShield of Georgia, Atlanta, Ga., USA
}

\section{Key Words}

Distance learning - Distance education - Undergraduate education - Medical education - Internet-based education - Tele-education - Telematics

\begin{abstract}
The term 'distance learning' represents a variety of educational models that have in common the physical separation of the educator and some or all of the students. Students can be reached through any combination of media: closed-circuit television, video and audio conferencing via telephone lines, and multimedia interaction via the internet. In the past decade, the expansion of distance learning has mirrored the rapid technological advances in the late 20th century that have resulted in a proliferation of educational programs available from an evergrowing number of institutions. This paper reviews the origins and current status of distance learning as an educational medium (including examples of excellent distance learning programs), describes the educational models underpinning distance learning, and discusses the opportunities and challenges for institutions and educators in developing distance learning-based curricula. The research method used was that of a modified systematic literature review. The findings of the literature review show an overwhelming number of distance learn-
\end{abstract}

\section{KARGER}

Fax +41613061234

E-Mail karger@karger.ch

www.karger.com

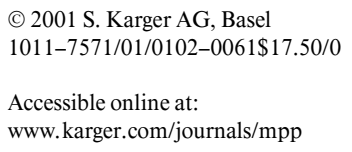

ing programs now available through a multitude of delivery mechanisms, especially the internet. With regard to the educational models for distance learning, three considerations influence the eventual choice: structure, process, and outcome. To ensure excellence in distance learning, six issues must be addressed: administration, financial resources, human resources, marketing, consumer issues, and the method of assessing distance learning programs. Changing social, professional, and lifestyle dynamics, as well as the rapid evolution of the educational principles of distance learning and the technology available, ensure that demand for lifelong learning will be significant. To respond to this demand, universities and other centers of higher education must recognize and meet the needs of learners who are quite different from the traditional student of the past. This paper presents an overview of the main issues facing institutions and educators who are considering distance learning as a part of their educational programs.

Copyright @ 2001 S. Karger AG, Basel

\section{Introduction and Overview}

The term 'distance learning' (DL) represents a variety of educational models that have in common the physical separation of the educator and some or all of the students

John Ross Maclean, MD, MBA

Director of Health Services Research, Department of Medicine

Medical College of Georgia

Augusta, GA 30912 (USA)

Tel. +1 706721 1684, Fax +1 706721 0504, E-Mail rmaclean@mail.mcg.edu 
Table 1. A sample of institutions promoting and delivering distance education and learning programs via the internet

\begin{tabular}{lll}
\hline Search term & Internet sites $^{1}$ & Examples \\
\hline Distance education & $3,195,460$ & American Distance Education Consortium [36]: an international consor-
\end{tabular}

Distance education 3,195,460 American Distance Education Consortium [36]: an international consortium of state and land grant institutions providing economic distance education programs and services

International Council for Open and Distance Education [37]

Distance Education Information, Tools, and Support Services [38]: a private company that links educators, students, retailers, and professionals in a single network

Harcourt Learning Direct [39]: a distance education provider of 'online learning experiences'

Distance learning $\quad 8,693,831 \quad$ Globewide Network Academy [40]: a distance education resource center with a free online searchable course catalog database, thousands of courses, programs, and academic support services

America's Learning eXchange [41]: a virtual yellow pages of training and education resources for career advancement

United States Distance Learning Association [42]: a source for information on DL curricula

Petersons's Distance Learning [43]: lifelong learning, on-line education and adult education; the site includes a search facility for accredited DL programs and online courses

\begin{tabular}{|c|c|c|}
\hline $\begin{array}{l}\text { Distance learning } \\
\text { in medicine }\end{array}$ & $2,206,965$ & $\begin{array}{l}\text { Academy on Natural Therapies [44]: formal degree programs including a } \\
\text { BSc in Nutrition and an MSc in Natural Therapies } \\
\text { Imperial College School of Medicine [44]: tele-education for clinical under- } \\
\text { graduates } \\
\text { University of Sheffield [44]: degree programs in nursing Informatics } \\
\text { UCLA [45]: advanced training for clinical specialists including a tour of the } \\
\text { 'Virtual Aneurysm' } \\
\text { National Library of Medicine and the National Institutes of Health [45]: } \\
\text { multiple collaborative video conferencing-based courses in medical educa- } \\
\text { tion and consultation } \\
\text { Tufts University [46]: a leading provider of education on the practice of } \\
\text { medicine under managed care }\end{array}$ \\
\hline
\end{tabular}

1 Sites found via a search at http://www.excite.com on 4th April 2001.

[1]. Students can be reached through any combination of media: closed-circuit television, video and audio conferencing via telephone lines, and multimedia interaction via the internet. A DL course is one in which at least $51 \%$ of the course is conducted through a DL or remote environment [2]. DL may be conducted via synchronous communication (student and teacher are both present at the same time for instruction) and asynchronous communication (no direct student-teacher interaction).

The evolution of DL has paralleled the history of communications and may be traced back almost 200 years to the earliest reliable mail services that enabled correspondence courses to be offered to enthusiastic students living remotely from an educational establishment. In the past decade, the expansion of DL has mirrored the rapid technological advances in the late 20th century that have resulted in a proliferation of internet, intranet, and computer-aided instruction courses (e.g., CD-ROM) available from an ever-growing number of institutions. To illustrate this point, table 1 presents a sample of the vast number of courses identified from an internet search using the terms 'distance education', 'distance learning', and 'distance learning in medicine'. For example, a search with the term 'distance learning' using one popular internet search engine identified 8,693,831 sites. 
Table 2. Search terms used in the review

\begin{tabular}{lll}
\hline Domain & & \\
\hline distance learning & education & technological teaching methods \\
\hline distance learning & undergraduate education & $\begin{array}{l}\text { tele-education } \\
\text { telematics }\end{array}$ \\
distance education & medical education & $\begin{array}{l}\text { teleconferencing } \\
\text { video conferencing }\end{array}$ \\
& & telemedicine \\
& & internet-based education \\
& &
\end{tabular}

Given the enormity of the subject matter that is embraced by DL, this paper seeks to review the origins and current status of DL as an educational medium (including examples of excellent DL programs), to describe the educational models underpinning DL, and to discuss the opportunities and challenges for institutions and educators in developing DL-based curricula.

\section{Methodology of Review}

The method used to undertake the literature review was adapted from the Cochrane Collaboration Handbook [3]. Note, however, that the review undertaken was not intended to be a systematic review or to incorporate meta-analysis techniques. The review incorporated the following steps:

\section{(1) Agreeing the Strategy for Review}

The authors met at the start of the project to agree on the aims and objectives to be addressed by the article, and the strategy for identifying appropriate evidence to review. Throughout the writing process, the authors met regularly to review progress on the article and to respond to peer review from local colleagues. In addition to formal research education, the authors all have extensive experience in searching electronic databases such as Medline and the Education Research Information Center.

\section{(2) Protocol Development}

The search terms used for the review are presented in table 2. The terms are based upon initial reading, past experience with literature searching, and iterative learning during the review process. Most terms are synonyms for DL, distance education, and technologybased teaching methods. Papers that discussed elementary and secondary education were excluded as were papers written in languages other than English or papers published before 1990. Initial activity focused on the content of electronic databases. The paucity of papers listed in the electronic databases expanded the search into internetbased resources.

\section{(3) Assessing Citations for Inclusion and Writing the Report}

Assessing the quality of papers and reports was challenging. 'Database citations can be assessed for relevance quickly, but it may be necessary to review a large number of citations to ensure that as many relevant papers as possible are identified and included. Similarly, it may be necessary to retrieve and review a large number of full text reports' [3]. Given the enormity of the resources available from searching the internet, the review was strict in adhering to articles of relevance to the paper. Interpretation of the papers and preparation of the report was undertaken solely by the authors. It is recognized that this process is open to criticisms of bias; therefore, unaffiliated reviewers were used to reduce the bias. In defense of the approach taken, Mulrow [4], and Oxman et al. [5] have noted that reviews of the same topic often disagree, and that neither the expertise of the reviewer nor peer review can guarantee the validity of a review.

\section{Current Status of DL}

Demand for perpetual learning continues to grow. As changes occur in nearly every career field, the need for accessible, focused, industry-specific learning has put increasing demands on lifelong education. The growth in DL will be shaped by a combination of factors: how responsive an institution is to student and market demands, the ability of an institution to provide students with access to campuses and DL technologies, and the local telecommunications infrastructure [6].

In addition, the advent of personal computers, the internet, and an increasingly technology-aware population have made DL a popular option for professional and personal advancement. Originally conceived as a substitute form of education, DL has developed into a preferred alternative for millions of people seeking education and training [7]. As an example of the phenomenal interest and growth in DL programs, we now provide a brief summary of the origins of DL and recent developments in the United Kingdom (UK), Middle East and North America.

Ranked among the top universities in the UK for the quality of its teaching and perhaps one of the most highly respected DL institutions in the world, the Open University (OU) is regarded as the 'gold standard' in DL. Since its creation in 1971, the OU has grown rapidly and with more than 200,000 students enrolled during the 1997- 
1998 academic period and 24,000 students taking university courses throughout Europe and other parts of the world (through partnership agreements with other institutions), the OU has also become the largest university in the UK [8]. Many OU courses have been independently acknowledged as being of an excellent standard. Indeed, 19 programs within the OU have been recognized as producing research work of near international quality and 7 more show evidence of national excellence. The OU regularly receives awards for innovations, e.g., the British Computer Society 'Information Technology' Award and the British Environment and Media Award for its innovative use of CD-ROM technology in the program 'Discovering Science' [8].

Leaders in the field of collaborative international educational curricula are the medical schools of the University of Aberdeen, Scotland, and the United Arab Emirate University. A study conducted between the two found that technological advances in video conferencing enabled easy, fully interactive learning among students from not only different local and national sites, but also across different continents and from different cultural backgrounds [9].

A DL-based Pediatric Intensive Care nursing course is offered by the British Columbia Institute of Technology in Vancouver, Canada. The course can be accessed at a certificate (30 credits) or degree (60 credits) level. Each element of the curriculum comprises a stand-alone learning package and utilizes the problem-based/case study approach [10].

In the United States, distance learning became a method of instruction not long after a reliable mail delivery service was developed. By the 1840s, Isaac Pittman had developed one of the first correspondence courses in the country, and in 1892, the University of Wisconsin offered the first American correspondence course catalogue [7]. In the intervening years progress in integrating technology centered on delivering TV/video-based products. However, it was not until the information technology revolution of the 1990s that the DL marketplace could undergo its next major transformation.

The number of DL programs offered at community colleges and universities across North America continues to increase at a rapid rate. For example, Petersons's 1994 guide to DL [11] listed 93 accredited distance education programs and the 1997 [12] guide listed more than 700. Data gathered in the last 2 years present a startling picture of the rapid emergence of DL in the education marketplace: (1) Forty-four percent of the college classes surveyed use e-mail [13]. (2) Thirty-three percent of the classes surveyed use internet resources as part of the syllabus [13]. (3) Forty-five percent of the undergraduates surveyed use the internet at least once a day [13]. (4) Fiftytwo percent of the faculty surveyed use the internet at least once a day [13]. (5) The Distance Education and Training Council, which is authorized by the US Department of Education to accredit institutions offering DL courses, estimates that there are presently three million students nationwide using DL methods [7]. (6) Fifty-five percent of the 2,215 four-year universities and colleges in the United States now offer off-site courses [14]. In the next 2 years that number will increase to $85 \%$ [15]. (7) Of 130 medical schools in Canada, the US, and Puerto Rico who responded to a survey regarding medical students' education for the 21 st century, 61 (47\%) described curricula that included computer-based and/or computerassisted instruction as well as other internet/intranet functions, although only 3 of the 61 included DL [16].

DL courses that are now available to students within one country are also available to students from other countries as well. For example, half of the students in Duke University's on-line MBA program are from countries other than the US, and the University of Florida offers courses to students in the UK and Europe. Likewise, students in the United States can access courses originating overseas [14]. Other institutions are using DL technologies as an opportunity to bring together disciplines that historically have had little interaction. For example, Charter Oaks State College in New Britain, Conn. offers on-line and video-based courses. One such course is in the Social Science Department and entitled The Economics of Health and Health Care [17].

Some states within the USA have demonstrated a greater commitment to DL than others. The state of Georgia is among the leaders. Over the past 8 years, Georgia has pioneered the development of a multifaceted approach to DL. Key aspects of Georgia's pioneering leadership are:

(1) Easier access to information in course availability and course registration through the development of a statewide register of higher education curricula. Since its inception in 1999, the participating public institutions have received more than 9,000 applications via the internet [18].

(2) Improved access to library facilities. The state's online library, GALILEO, enables students to access the resources of the System's 34 institutions [18].

(3) Statewide infrastructure to support DL program delivery. The Georgia Statewide Academic and Medical System is an interactive video conferencing system that 
allows an instructor to teach students in multiple locations by linking 400 sites across Georgia. Students are able to reduce travel time by selecting a site at a convenient nearby location [2].

The aforementioned three initiatives have resulted in a remarkable increase in public interest and participation in DL across Georgia:

(1) A 1999 statewide survey of 500 registered voters indicated that over $40 \%$ of those polled would be interested in attending a college or university in the next 3 years. Of that number, over $60 \%$ indicated that they would use either the internet or Georgia Public Broadcasting to obtain additional education [2].

(2) In the year 2000, internet-based offerings comprised 31,560 credit hours among the 34 public colleges and universities in the University System of Georgia [2].

(3) Southern Polytechnic State University noted a dramatic increase in the number of students choosing to earn degrees via DL. In the fall of 1997, 69 students were enrolled in an on-campus program in quality assurance compared to 29 students enrolled in the on-line program. In the fall of 2000, 19 students were enrolled in the same on-campus program while 76 students were enrolled in the on-line course [2].

(4) The opportunity for future internet-based curricula was reinforced by a recent study in Georgia revealing that $75 \%$ of respondents had access to the internet at home or at work [19].

\section{Model of DL}

Three considerations influence the eventual choice of a DL model: structure, process, and outcome. The three considerations are broad descriptions of educational methods that are integral to the design and delivery of a DL program, therefore to some extent they overlap one another.

\section{Structural Considerations}

This centers on the infrastructure available to deliver the program. From a structural perspective there are three DL course development models: the distributed classroom, independent learning, and open learning plus class [1]. The distributed classroom model involves the use of interactive telecommunication technologies to extend a classroombased course from one location to a group of students at one or multiple distant locations. The typical result of this model is a course that consists of both on-site and distant learners. In this model, the faculty and the institution con- trol the pace and place of instruction [1]. A representative course could involve classroom sessions, distance sessions, teleconferences, e-mail exercises, and course projects that are performed in teams in a dispersed environment. Collaboration on cases and projects can be required and distance sessions use a variety of methodologies to discuss materials, access outside experts, and simulate realworld scenarios. The independent learning model allows students more flexibility than the distributed classroom model. Independent learning frees students from having to be in a particular place at a particular time. Students are provided a variety of materials including a course guide and detailed syllabus. Students are also provided access to a faculty member who gives guidance, answers questions pertaining to course materials, and evaluates the student's coursework. Contact between the individual student and the instructor is achieved by using one or a combination of the following technologies: telephone, voice mail, computer conferencing, electronic mail, and regular mail [1].

The open learning plus class model involves the use of a printed course guide and other media such as videotapes, CD-ROMs, or computer disks to allow the individual student to study at his or her own pace. The student also has access to interactive telecommunication technologies for group meetings available to all students enrolled in the course [1].

\section{Process Considerations}

Process refers to the instructional approach. There are numerous media for delivering a DL course including traditional correspondence courses delivered by mail, electronic mail, television, radio, and satellite [7]. However, as with traditional education, the various DL models have been developed around the central components of the instructional process rather than out of consideration for the medium of delivery. The central components of the instructional process are: presentation of content; interaction with faculty and peers; practical application; and, student assessment [1]. Superimposed on the aforementioned multiple media for delivering DL has been the emergence of the internet in the past decade. Labeled by some as 'outbound learning', the now ubiquitous internet promises a paradigm shift in instructional approaches, at the same time offering the potential to become an ideal medium to respond to the public demand for further education and professional development. For example, the internet radically alters the traditional structure and process of students attending a 'bricks-and-mortar' campus to receive their higher education in that a physical campus is not required at all [14]. In fact, the learners interact with 
Table 3. 'Process' considerations in selecting a DL model: advantages and disadvantages of each medium

\begin{tabular}{|c|c|c|}
\hline $\begin{array}{l}\text { Medium of } \\
\text { delivery }\end{array}$ & Advantages & Disadvantages \\
\hline $\begin{array}{l}\text { Traditional } \\
\text { classroom }\end{array}$ & $\begin{array}{l}\text { faster and easier material preparation } \\
\text { high level of student/educator interaction } \\
\text { instant feedback } \\
\text { no additional technological staff needed }\end{array}$ & $\begin{array}{l}\text { rigid scheduling } \\
\text { limited locations } \\
\text { educator-imposed pacing }\end{array}$ \\
\hline $\begin{array}{l}\text { Correspondence } \\
\text { (mail delivery) }\end{array}$ & $\begin{array}{l}\text { faster and easier material preparation } \\
\text { easy maintenance } \\
\text { can be done at any time }\end{array}$ & $\begin{array}{l}\text { requires high level of student independence } \\
\text { slow delivery } \\
\text { limited amount of feedback } \\
\text { low amount of student/instructor interaction }\end{array}$ \\
\hline Internet & $\begin{array}{l}\text { fast delivery } \\
\text { moderate amount of student/educator } \\
\quad \text { interaction (compared to mail) } \\
\text { wider audience } \\
\text { high degree of convenience } \\
\text { often self-paced }\end{array}$ & $\begin{array}{l}\text { cost of new technology (hardware and software) } \\
\text { additional training of educational staff } \\
\text { additional technology staff required } \\
\text { maintenance of equipment and sites } \\
\text { more intensive material preparation } \\
\text { moderate amount of student/educator interaction } \\
\quad \text { (compared to traditional) }\end{array}$ \\
\hline $\begin{array}{l}\text { Computer-aided } \\
\text { instruction, e.g., } \\
\text { CD-ROM }\end{array}$ & $\begin{array}{l}\text { fast delivery } \\
\text { high degree of convenience } \\
\text { often self-paced }\end{array}$ & $\begin{array}{l}\text { requires high level of student independence } \\
\text { limited amount of feedback } \\
\text { low amount of student/instructor interaction } \\
\text { cost of new technology (hardware and software) } \\
\text { additional training of educational staff } \\
\text { additional technology staff required } \\
\text { maintenance of equipment and sites } \\
\text { more intensive material preparation }\end{array}$ \\
\hline $\begin{array}{l}\text { Video } \\
\text { conferencing }\end{array}$ & $\begin{array}{l}\text { less intensive material preparation } \\
\quad \text { (compared to internet) } \\
\text { high student/educator interaction } \\
\text { instant feedback }\end{array}$ & $\begin{array}{l}\text { cost of new technology (hardware and software) } \\
\text { additional training of educational staff } \\
\text { additional technology staff required } \\
\text { maintenance of equipment and sites }\end{array}$ \\
\hline
\end{tabular}

their teacher entirely on-line with no face-to-face teaching. One of the many challenges of 'outbound learning' as a means to deliver DL programs is the development of teaching faculty who have the skills and confidence to teach 'virtual students' as well as students in 'real' classrooms. The numerous advantages and disadvantages for each approach to the process considerations in DL are described in table 3.

\section{Outcome Considerations}

Outcome refers to how the students will be evaluated throughout the educational program. Course developers can base DL instruction on three models: the time-based model, the competency-based model, or a combination of the two. The time-based model establishes a prescribed time-line of events, e.g., midterm and final tests, and the meeting of a set of complex cognitive, behavioral, and attitudinal skills. A competency-based model establishes the desired skills or outcomes via a competency test, e.g., demonstration of a practical skill. And, of course, a combination of the first two models allows the educator to choose the key functions of each model to fit the needs of the course and the students [20].

In summary, identification of the most suitable model for a DL program is a multifaceted decision. The models presented offer a starting point in deliberations on the most appropriate approach to the DL program under consideration.

\section{Ensuring Excellence in DL}

A high quality product with a satisfied customer is the aim of both educational institutions and educators. In planning for this aim, six issues face those considering a DL-based approach: 


\section{(1) Administration}

Administrative challenges occur at three levels: national, regional, and local. At the national level challenges include the criteria used to determine eligibility for government funding and the criteria for monitoring and evaluating DL programs. At present, in the US both sets of criteria are heavily biased towards traditional formats of instruction such as the classroom [15]. At the regional level, the academic accreditation process still uses campuscentered, classroom-based instruction as the basis for the review and evaluation of programs. However, more recently, procedures that specifically address the evaluation of distance education programs are being created [15].

Institutional level challenges occur in the administrative structures, procedures, rules, and regulations that serve traditional students but are inappropriate for distance learners. Registration, tuition payment, student support, library services, and scheduling are areas that are affected by the current set of procedures.

The issue of intellectual property rights is a concern for both the faculty developer and the providing institution. In the United States, ownership and copyright use are codified within the Copyright Statute (Title 17). However the language can be interpreted in various ways and does not completely address the new technologies. A committee within the American Association of University Professors recommends that the Association develop a policy that presumes that the ownership of all academic work resides with the individual faculty member or members who create that work [21].

\section{(2) Financial Resources}

Although the cost per unit of data has decreased, the cost of developing DL curricula has risen. These costs are directly related to an institution's ability to expand into DL and the cost of the technological infrastructure can vary significantly for individual schools and students. In 1962, a high-quality instructional television program cost about $\$ 165$ per 15 -min program to produce. Today the cost of developing a fully interactive DL program has been placed at approximately $\$ 3,000$ per minute [22].

The recent growth and surge in consumer interest in DL puts pressure on universities to add to their curricula or to repackage existing curricula. One way to meet this demand is for an institution to analyze the fixed and variable costs of repackaging existing courses. Measurement of the cost associated with developing an individual course is difficult because the inputs are often shared with numerous activities [23]. Burton [23] has identified the variable and fixed costs of developing a video-based DL program: fixed costs (faculty time, production of logo, secretarial support) and variable costs (video production, videotapes and tape copying, travel, printing and postage, and miscellaneous).

Unfortunately, the prohibitive cost of electronic technology has caused many smaller colleges to become victims of the 'divide' between institutions that can and cannot afford to invest in DL. However, because a wired campus is essential for survival, many institutions are collaborating with one another and with private corporations to provide the updated technology necessary for their continued existence and expansion. This is of particular reassurance for institutions serving less fortunate communities such as the Historically Black Colleges and Universities in the US [24].

However, Sherry [22] advises against naive overconfidence about the likely success of an educational program just because it is offered in a DL format and quotes Holloway and Ohler [25]: 'Little happens of any magnitude without administration buy-in, and the best way to achieve that is to succeed on a small level first. Put most of your effort into finding the right people rather than the most exciting technology.'

\section{(3) Human Resources}

Institutional faculty will lead the development and delivery of DL curricula. To capitalize on the opportunities that DL offers, educators must recognize the level of commitment and resources required to be successful in designing a DL program. Table 4 describes the intensity of institutional and educator resources required.

An institution delivering a DL program must also recognize the additional commitment required of individual educators to the development of a DL program. For example, it is an uncommon practice to name DL in a professor's job description. Assigning faculty to DL as part of their workload is also an uncommon practice. Faculties who conduct DL are rarely evaluated as carefully as a conventional classroom lecturer. However, seldom does an institution grant a salary increase in recognition of work done in DL [15] and peer review of DL programs remains challenging as DL programs and correspondence education in general are often perceived as second-class versions of on-campus programs [20].

\section{(4) Marketing}

Student demand and interinstitutional competition are major factors influencing providers of DL. It is estimated that at present $85 \%$ of US college graduates will need and/or seek further education and that this figure 
Table 4. Intensity of institutional and educator resources required to assure success in DL

\begin{tabular}{|c|c|c|c|c|c|}
\hline \multirow[t]{2}{*}{ Domain } & \multicolumn{5}{|c|}{ Medium for DL program delivery } \\
\hline & traditional & correspondence & internet & $\begin{array}{l}\text { CAI } \\
\text { (e.g., CD-ROM) }\end{array}$ & $\begin{array}{l}\text { video } \\
\text { conferencing }\end{array}$ \\
\hline Preparation & low & low & high & high & moderate \\
\hline Speed of delivery & slow & extra slow & fast & fast & slow \\
\hline Convenient for student & low & moderate & high & high & low \\
\hline Level of student independence & low & high & high & high & moderate \\
\hline Student/educator interaction & high & low & $\begin{array}{l}\text { low to } \\
\text { moderate }\end{array}$ & low & high \\
\hline $\begin{array}{l}\text { Scheduling and } \\
\text { location }\end{array}$ & rigid & flexible & flexible & flexible & rigid \\
\hline Audience & narrow & $\begin{array}{l}\text { narrow to } \\
\text { moderate }\end{array}$ & wide & wide & $\begin{array}{l}\text { moderate to } \\
\text { wide }\end{array}$ \\
\hline Additional cost of technology & low & low & high & high & high \\
\hline $\begin{array}{l}\text { Additional training for } \\
\text { educational staff }\end{array}$ & low & low & intensive & intensive & $\begin{array}{l}\text { moderate to } \\
\text { intensive }\end{array}$ \\
\hline Additional technology staff & low & low & high & high & high \\
\hline Maintenance of equipment/sites & low & low & high & high & high \\
\hline
\end{tabular}

The terms used (e.g., 'low') do not mean the effort required of the task itself but the amount of time, effort, and resources required to deliver the DL program. $\mathrm{CAI}=\mathrm{Computer}$-aided instruction.

will remain as high as $74 \%$ over the next decade. In numerical terms this amounts to providing education and training to 50 million workers [14].

According to Willis as cited by Sherry [22, 26], adult learners have a wide variety of reasons for pursuing a distance education: time, distance, finances, opportunity, and contact with other students from different social, cultural, economic, and experiential backgrounds. Of students entering the OU, two thirds are between the ages of 25 and 44 . Because approximately $70 \%$ of the undergraduate students remains in full-time employment throughout their studies, nearly all of the new students enroll on a part-time basis. Out of OU's entire student body of 200,000 , more than 40,000 enrollees study interactively on-line at home and/or in the workplace. At the time of enrollment, over one third of the students starting undergraduate courses have qualifications below conventional university entry requirements. In spite of this disadvantage, nearly $70 \%$ of the students successfully complete their courses [8].

With the average annual cost of higher education having more than doubled in the past 20 years within the US, many students have sought more affordable means to advance their knowledge and careers. Because viewing a video requires $30-40 \%$ less time than listening to a classroom lecture, DL offers potential students a new way of fitting educational needs into the demands of career and family by providing on-demand learning and learner control. On-demand learning allows instruction to be available when and where students need it while learner control provides students a learning method that better fits their needs. Students can skip what is not needed or redo what is not understood. Better access to specialized expertise allows students to contact distant experts/instructors without the time and expense of travel [14].

New technology provides enhanced motivation for students to pursue additional education as well as increased safety. DL provides potential opportunities for students to learn a hazardous procedure without being in a hazardous situation. Students learn more because technology-based interactive learning is more interesting. And, with corrective feedback and mastery learning, better test results, knowledge retention and/or increased job performances are produced [14].

Thus, DL has the potential to tap an expanding market, increase revenue, put an institution on the "cutting edge', and meet an expanding need in society. The greatest advantage to putting a course on the web is the potential for a wider audience [27]. For educational institutions, adding DL to the curricula necessitates multiple commitments to quality assurance [14]: (a) better quality control: consistency in DL course delivery; (b) greater 
flexibility: fluctuations in student numbers and/or backgrounds must be accommodated more easily; (c) improved accountability: automatic collection of performance data to administer and identify learning problems or verify learning; (d) faster revision of curricula: changes and updates must be made quickly; (e) reduced delivery costs: after development, DL may be relatively less laborintensive than classroom instruction; (f) access to a broader audience: schools can attract students from outside the area and sell educational services to community and outside businesses, and (g) fewer resources required per student: scheduling scarce resources is made easier by reaching more students at more sites.

However, caution must balance naive overenthusiasm. In a survey of training managers from blue chip Australian companies, $80 \%$ ( 45 of 57) viewed on-line learning as an ineffective way to educate [28]. In a similar survey conducted in the USA, 239 human resource professionals were surveyed regarding their perceptions of distance learning: $77 \%$ (184 of 239) believe that an on-campus degree at an accredited institution is more credible than one earned through an internet institution. However, $61 \%$ (146 of 239) reported that although not as credible, the on-line degree was acceptable [29].

\section{(5) Consumer Issues}

The reasons most often cited by DL students for seeking additional education were career change, career advancement, and personal enrichment. Closely linked to these motivating factors was the life stage that many students found themselves, i.e., mid-career with family commitments such as childcare, work schedules, family obligations, and long drive times to campus-based courses [30]. Combining DL education with a home life brings additional challenges, foremost of which is maintaining self-motivation.

Lyall and McNamara [31] reported that maintaining a high level of motivation was necessary to complete a DL course and reiterated that studying via DL was more challenging than studying on-campus. In addition, participants with family commitments were more certain of their goals and more highly motivated than those without. Among the motivators listed by the students were: (a) vocational; upgrade job skills, facilitate a change in career, or gain more prestigious employment; (b) financial: become eligible for a higher paying position; (c) personal: increase self-esteem or improve social position, and (d) academic: intellectual fulfillment and challenge.

Researchers have also found that students who are successful in DL courses apply certain primary learning strat- egies. These strategies include examination competency, concentration, and time management skills. In contrast, there was little difference between those who succeeded and those who did not in the secondary learning strategies of active learning, diligence, and positive attitude [22].

Student characteristics such as active listening and the ability to work independently seem to be crucial for success [22]. Lyall and McNamara [31] found that a student's perceptions and intentions are more important in how a student approaches learning than other concerns. Deep learners begin with the intention of understanding and maintaining interaction with the content. On the other hand, surface learners begin with the intention of completing the required tasks. A third approach uses both deep and surface learning styles. This is the 'strategic approach', which includes planning, time management, and the use of study skills. Using these approaches, a few very disciplined participants were able to keep to their time plan, with some being ahead of schedule; however, most had fallen behind by the time they were halfway through the course [31].

By its very nature DL may be associated with isolation of the student from the teacher and other students. Lyall and McNamara [31] identified isolation as both a potential problem and a way to increase student independence and self-reliance. However, it is interesting to note that when Lyall and McNamara's [31] survey respondents were asked if they would rather study on-campus, nearly all replied no. Thus, to ensure excellence in DL, educators need to recognize the potential problems faced by balancing student motivation while minimizing isolation.

\section{(6) Assessment of DL Programs}

(i) In a comparison of effectiveness of DL- and classroom-based curricula titled 'What's the Difference?' written for the American Federation of Teachers and the National Education Association, the report noted that there was a scarcity of original research dedicated to explaining or predicting phenomena associated with DL and that there were several key shortcomings of the research that was conducted. The shortcomings of the existing research on the quality and effectiveness of DL programs were [32]:

(ii) Little control for extraneous variables with an inability to demonstrate a relationship between the education received and its impact on knowledge, skills, and behavior change.

(iii) The educational assessment instruments were often of questionable reliability and validity. 
The American Federation of Teachers and the National Education Association paper concluded that there was an urgent need for further rigorous study of [32]: (a) the outcome of DL programs, (b) differences amongst students, (c) the higher dropout rate for distance learners, (d) relationship of learning style to technology, (e) interaction of multiple technologies, (f) theory development, and (g) effectiveness of digital 'libraries'.

A contentious issue in the academic world is the credibility and legitimacy of institutions and degrees being offered in the DL medium. In the United States, the prejudicial term most often used for places that offer unaccredited degrees is 'degree mill'. The US Office of Education, in March 1974, defined a 'degree mill' as an organization that awards degrees without requiring students to meet established educational standards [33]. Degree mills exist all over the world and have been around for hundreds of years. During the 1980s, US federal intervention significantly reduced the number of suspect schools; however, the proliferation of new technologies such as inexpensive laser printers, color copiers, and, most significantly, the internet has enabled a significant comeback in DL programs of questionable quality [34].

\section{Conclusion}

As DL emerges as a major force in the education world, a controversial issue that remains is the social divide between those with and those without access to technologies that enable self-development. The issue is often labeled the 'digital divide'. A recent report by the Institute for Higher Education Policy [35] indicates that there has been overall growth in internet use plus a significant increase in internet accessibility for families with an annual household income below US $\$ 25,000$. The reasons stated for this narrowing of the digital divide are the continuing decrease in computer prices, increased technological ease of use, and improved access to the internet in professional, academic, home and community environments. As the digital divide continues to decrease, experts believe the market for DL programs will grow. Universities and other centers of higher education face a future quite different than that of the annual fall intake of students on campus. Changing social, professional and lifestyle dynamics, emerging telecommunications technologies, and the rapid evolution of the educational principles underpinning DL program development ensure that future demand will be significant. Where challenges remain, these need to be addressed by institutions, educators, and students to optimize the outcome for all.

\section{References}

1 Three models of distance education. Institute for Distance Education web site. Available at: http://www.umuc.edu.ide/modldata.html.

2 Meyers A: Worldwide colleges: The reach of computers and the internet is breaking down barriers to study such as time and distance. Atlanta J Constitution, Sept 10, 2000;2:10.

3 Sackett D, Oxman A: Cochrane Collaboration Handbook. Oxford, Cochrane Collaboration and Health Information Research Unit, 1996.

4 Mulrow CD: The medical review article: State of the science. Ann Intern Med 1987;106:485488.

5 Oxman AD, Guyatt GH, Singer J, Goldsmith $\mathrm{CH}$, Hutchison BG, Milner RA, Steiner DL: Agreement among reviewers of review articles. J Clin Epidemiol 1991;44:91-98.

6 Assuring equitable access: A distance learning vision for Florida 1997. Florida Public Post Secondary Distance Learning Institute web site. Available at: http://fcn.state.fl.us/institute/finivis.html.

7 Factoids. Instructional Systems, Inc. web site. Available at: http://isinj.com/wellspring.html.

8 Open University: About us. Available at: http:// www.open.ac.uk/about/html.
9 Norman JN, Brebner JA, Brebner EM, Lloyd OL, Ruddick-Braclen H, Ahmed M, El Sadig $\mathrm{H}$, Catto GRD, Ledingham I McA: Telematics in undergraduate teaching. Med Educ 1995;29: 403-406.

10 Hewitt-Taylor J: Paediatric intensive care nursing education by distance learning: An example from Canada. Intensive Crit Care Nurs 1998;14:137-143.

11 Petersons's Annual Guide: Graduate Programs in Business, Education, Health, Information Studies, Law and Social Work. Princeton, Petersons's Guides, 1994.

12 Petersons's Annual Guide: Graduate Programs in Business, Education, health, Information Studies, Law and Social Work. Princeton, Petersons's Guides, 1997.

131998 National Survey of Information Technology in Higher Education: Colleges struggle with IT planning. November 1998. Campus Computing Project web site. Available at: http:// www/campuscomputing.net.html.

14 Distance learning white paper - product applications. Enterprise Video Networking web site. Available at: http://www.fvc.com/apps/dist_ learning_wp.html.
15 Moore MG (ed): Administrative barriers to adoption of distance education. Am J Distance Educ 1994;8:No. 3. Penn State University web site. Available at: http://www.ed.psu.edu/ acsde/ajde. Accessed January 17, 2001.

16 Anderson MB (ed): A snapshot of medical students' education at the beginning of the $21 \mathrm{st}$ century: Reports from 130 schools. Acad Med 2000;75(suppl 9).

17 Charter Oaks State College: Distance Learning. Available at: http://www.cosc.edu/dl/course offering_list.htm.

18 Salzer J: Online U. is newest state school. Atlanta J Constitution, May 5, 2000;D1, D6.

19 IT is changing: How middle and south Georgia residents learn and work. University System of Georgia web site. Available at: http://georgiaglobe.org/script...

20 Boettcher JV: Distance learning: Looking into the crystal ball. July 1996. Available at: http:// www.cren.net/ jboettch/jvb_cause.html.

21 Rubiales D, Steely MT, Wollner CE, Richardson JT, Smith MF for the American Association of University Professors: Report on distance learning. November 14, 1997. Available at: http://www. aaup.org/dlrptxt.html. 
22 Sherry L: Issues in distance learning. Int J Educ Telecommun 1996;1:337-365.

23 Burton RO Jr: Costs and benefits of increasing access to a traditional agricultural economics course. Am J Agric Econ 1998;80:979-983.

24 Institute for Higher Education Policy for Council for Higher Education Accreditation. An ongoing study on distance learning. June 1999. Council for Higher Education Accreditation web site. Available at: http://www.chea.org/ Commentary/distance-learning.html.

25 Holloway RE, Ohler J: Quoted by Sherry L: Issues in distance learning. Int J Educ Telecommun 1996;1:337-365.

26 Willis B: Cited by Sherry L: Issues in distance learning. Int J Educ Telecommun 1996;1:337365.

27 How on-line courses are developed. Columbia University ed Tech web site. Available at: http://www.tc.columbia.edu/academic/edtech/ revhome/discuss/html.

28 Liddell C: The ABC of online education. November 14, 2000. Australia's Internet Industry Portal web site. Available at: http://www. australia. Internet.com/r/article/jsp/sid/57175. html.
29 Hirst K (ed): Perceptions of distance learning. 2000. Distance Learning web site. Available at: http://distancelearn...learn/library/weekly/ aa1116000a.html.

30 Use the internet to earn degrees. University System of Georgia web site. Available at: http:// georgiaglobe.org/script...

31 Lyall R, McNamara S: Influences on the orientations to learning of distance education students in Australia. Open Learning 2000;15: 107-121.

32 Phipps R, Merisotis J: What's the difference: A review of contemporary research on the effectiveness of distance learning in higher education. Institute for Higher Education Policy; 2000.

33 Information on degree mills: What is a degree mill. Adult Education and Distance Learner's web site. Available at: http://www.virtualuniversities.net/information.html.

34 Bear JB, Bear MA: Degree mills. July 1996. Consumer education web site. Available at: http://www.quackwatch.com/04ConsumerEducation/dm0.html.

35 Institute for Higher Education Policy for the Council for Higher Education Accreditation: The expanding universe of distance learning. Distance Learning Higher Educ Febr 1999.
36 American Distance Education Consortium web site. Available at: http://www.adec.edu/.

37 International Council for Open and Distance Education web site. Available at: http:// www.icde.org/.

38 Distance Education Information, Tools and Support Services resource page. Distance-Educator web site. Available at: http://www.distance-educator.com/.

39 Harcourt Learning Direct web site. Available at: http://www.lifelong-learning-publisher-com/.

40 Globewide Network Academy web site. Available at: http://www.gnacademy.org/.

41 America's Learning eXchange web site. Available at: http://www.alx.org/.

42 United States Distance Learning Association web site. Available at: http://www.usdla.org/.

43 Petersons's Distance Learning web site. Available at: http://www.lifelonglearning.com/.

44 Department of Information resource page. University of Portsmouth web site. Available at: http://www.dis.port.ac.uk/.

45 Internet 2 web site. Available at: http://apps.internet2.edu/demos2000/.

46 Tufts University web site. Available at: http:// www.tufts.edu/

\section{Additional Resources}

Readers who are interested in finding out further information about DL are directed to the list of references, journals, and web sites that follow.

(1) A wide array of associations and organizations that can be accessed via the internet. All sites listed at (http://directory.nets...ion/distance Learning/associatins):

Association for Applied Interactive Multimedia

Commonwealth of Learning

European Association for Distance Learning

European Association of Distance Teaching Universities

International Centre for Distance Learning (ICDE)

International Council for Open and Distance Education

International Visual Literacy Association

SCOP The ICDE Standing Conference of Presidents of Open and

Distance Learning Institutions

University Continuing Education Association

Web-Based Training Information Center (WBT)

(2) Other web sites also of interest:

Association for the Advancement of Computing in Education: http://www.aace.org

Centre for Distance Learning - On-line Information Service: http://www.scps.nyu.edu/faculty

Distance Learning Association: http://www.discoverysystems.com

Distance Learning on the Net: http://www.hoyle.com/distance/portals.html
ERIC Clearinghouse on Information and Technology: http://ericir.syr.edu

Journal of Information Technology: http://www.tandf.co.uk/journals

(3) International publications that address DL issues:

Distance Education, journal, Australia

The Distance Educator, newsletter

Epistolodidaktika: The European Journal of Distance Education, UK

IEC News, newsletter, UK

Indian Journal of Open Learning, India

Istruzione A Distanza (IAD), journal, Italy

Journal of Distance Education, Canada

The Journal of Distance Learning, New Zealand

Open Forum: Distance Education and Open Learning, Australia

Open Learning, journal, UK

Open Praxis, newsletter, Norway

Revista de Educacion a Distancia, journal, Spain

(4) Regional and national publications in DL:

CIFFAD (Consortium International Francophone de Formation à Distance), bulletin, France

Comlearn, news publication, Canada

Communiqué, newsletter, Canada

DEANZ Bulletin (A Distance Education Association of New

Zealand), newsletter, New Zealand 
DEH (Distance Education in Health) News, newsletter, Kenya DEOSNEWS (Distance Education Online Symposium), online journal, USA

DERUN (Distance Education Research Update Newsletter), Australia

Distance Education and Training Network Newsletter, USA

Distance Education and Technology Newsletter, USA

DLA Newsletter, South Africa

EADTU (European Association of Distance Teaching Universities), newsletter, Netherlands

EDEN Newsletter (European Distance Education Network), UK

EUROSTEP Courier, newsletter, Netherlands

Indian Journal of Distance Education, India

Kakatiya Journal of Distance Education, India
Media and Technology for Human Resource Development, India Never Too Far, newsletter, Thailand

ODLAA (Open and Distance Learning Association of Australia) Times, newsletter, Australia

Online Chronicle of Distance Education and Communication, newsletter, USA

On Pirade, newsletter, Solomon Islands

OLS (Open Learning Systems) News, UK

Pakistan Journal of Distance Education, Pakistan

Radio y Educacion de Adultos, Spain

Saturnova, newsletter, Netherlands

Using Telematics in Education and Training: The European Newsletter, UK 